\title{
PASTOREIO, GOVERNO E OS LIMITES DO ENTENDIMENTO: SOBRE A CONDIÇÃO ÉTICA DOS CÃES NO SERTÃO CEARENSE
}

\author{
Jorge Luan Teixeira ${ }^{1}$
}

${ }^{1}$ Universidade Estadual Vale do Acaraú (UVA), Sobral/CE, Brasil

\section{Introdução}

Os ataques de cães aos rebanhos ovinos e caprinos são eventos relativamente comuns no sertão cearense. ${ }^{1}$ Todo proprietário ou trabalhador rural $^{2}$ que tem ou teve cães e ovelhas já lidou mais de uma vez com um desses ataques e com suas implicações práticas nas relações com os vizinhos e com um público mais amplo que, testemunhando, narrando e avaliando o episódio, contribui ativamente no seu desenrolar.

Geralmente à noite, os cães atacam rebanhos ou da sua vizinhança, ou de localidades a quilômetros de distância, causando prejuízos aos criadores. Se para a maioria dos habitantes dos sítios os cachorros são bichos muito prezados, aqueles que atacam os rebanhos produzem uma espécie de ira coletiva, ao passo que o sentimento do seu dono parece oscilar entre a raiva, a frustração e, sobretudo quando preza bastante o animal, a tristeza. O ataque gera algo como um curto-circuito moral e problematiza a concepção a priori dos animais como seres inocentes e com pouco entendimento, o que leva à tomada de decisões extremas pelos humanos.

Na maioria das vezes, a solução encontrada para esses bichos é a morte, e são comuns os casos em que o dono do cão não apenas é encarregado de matá-lo, como faz questão de fazê-lo. Nem todos os ataques, contudo, se resolvem tão facilmente: nem sempre há evidências de que foi um cachorro 
específico que 'pegou' a criação, e a situação se configura a partir de fofocas e trocas de acusações, quando não resulta em atitudes mais controversas feitas na calada da noite, como o envenenamento dos cães.

Em trabalho anterior sobre o tema escrito em parceria com Dibe Ayoub (Teixeira \& Ayoub 2016), discutimos as tensões, as negociações e as reparações que circulam em tais ataques e defendemos que a dinâmica de englobamento ético entre os cachorros 'viciados' e os seus donos humanos permite dizer que, do ponto de vista dos nossos interlocutores, a vida em tais localidades rurais é vivida como uma espécie de "comunidade moral interespecífica". Em consonância com o que observaram outros autores (e.g. Andriolli 2011; Pereira 2015; Andriolli \& Pereira 2016), afirmamos que as ações e os movimentos animais têm papel crucial na constituição e na negociação cotidianas dos ambientes rurais, podendo estabelecer, solidificar ou comprometer os vínculos entre os seres humanos e, por certo, entre os próprios bichos e os humanos, sejam eles os seus donos ou não.

Minha intenção neste artigo, a partir dos achados de pesquisa posterior (Teixeira 2019), é, por assim dizer, dar um passo atrás na argumentação em relação ao que foi discutido em trabalhos anteriores. A pergunta que me faço poderia ser formulada nos seguintes termos: Por que mesmo sendo em princípio considerados 'inocentes' e potencialmente inimputáveis os cães que atacam criação são/devem ser mortos? Dito de outro modo, por que essa solução radical é preferida às outras e tida como a mais (ou a única) apropriada?

Defendo que a resposta para esta pergunta não pode prescindir da descrição da condição ética dos animais no sertão cearense tal como concebida pelos sertanejos. Com esse intuito, centro atenção nos conceitos de pastoreio, governo e entendimento, que me parecem orientar as reflexões e as soluções formuladas a partir dos ataques. Ao mesmo tempo, ao chamarem a atenção para dois temas caros à reflexão (sobre a) moral - a responsabilidade e a liberdade -, pastoreio, governo e entendimento permitem ver de quais formas os sertanejos concebem os animais (e os cães, especificamente) como "sujeitos éticos" mais do que como seres com mero "significado ético" para os humanos (Laidlaw 2014).

Em diálogo com parte da produção recente sobre o tema, penso a ética como imanente à ação e como uma dimensão da vida ordinária, não como "o foco de interesse de metafísicos falando ou pensando aquela vida a distância"3 (Lambek 2015: 27) ou como um campo específico, discreto, da Antropologia (Lambek 2010; Laidlaw 2014). Ao invés de escalar "as alturas" do pensamento humano (Das 2015: 53) afirmando ou buscando uma ética e uma pragmática transculturais e pretensamente universais, trata-se de 
uma "descida" ao ordinário, nos termos de Veena Das (2007, 2012, 2015), que busca pensar com os interlocutores acerca das pequenas disciplinas e reflexões da sua vida cotidiana que permitem conceber essa vida como ética (Das 2015: 54).

Não se trata tampouco de centrar a descrição na obediência dos interlocutores a normas de conduta, regras, leis, códigos, tradições etc., supondo nesse esforço, tal como os utilitaristas criticados por Bernard Williams (2005), a sua comensurabilidade. A proposta dessas(es) antropólogas(os) é observar de perto e etnograficamente as ações levadas a cabo e as reflexões que, explícita ou sutilmente, seguem de perto e são ensejadas por aquelas ações do dia a dia. Os tipos de julgamento, de atenção e de sensibilidade em questão são, portanto, parte indispensável da vida vivida com os outros. O ponto que destaco neste trabalho é que, ao pensar sobre a vida no meio rural, entre esses "outros" com os quais é necessário lidar estão incluídos os bichos de criação, concebidos não apenas como objetos ou patrimônio, mas também como sujeitos.

Embora a noção de "ética ordinária" acima sumarizada me pareça produtiva para pensar sobre o dilema que atravessa os ataques dos cães aos rebanhos ovinos, cabe destacar que, grosso modo, as elaborações daquelas(es) autoras(es), ou de outras(os) que com elas(es) dialogam não tiveram como foco de interesse principal as relações entre humanos e animais. Por isso, penso que as formulações sertanejas sobre o estatuto dos bichos de criação podem contribuir no andamento desse debate ao chamarem a atenção para ações, sensibilidades e reflexões eticamente percebidas de seres não humanos.

\section{Cães como sujeitos e objetos do 'pastoreio'}

Cães são alguns dos animais que povoam os sítios do sertão cearense: se em uma casa específica não há um deles, é bem provável que algum vizinho possua um desses bichos. Na maioria das vezes, muitos daqueles que têm um bom cachorro que os auxilia decisivamente na lida com os rebanhos ou na prática venatória não o venderão por pouca coisa: há relatos de quem recusou trocar esses companheiros por dinheiro suficiente para comprar uma boa cabeça de gado. ${ }^{4}$

Em calçadas, terreiros e alpendres, os cachorros - ora deitados, ora farejando as redondezas, ora brincando uns com os outros - circularão os sertanejos que conversam; mas que não tentem adentrar as residências ou interagir com as visitas, pois serão sumariamente afastados aos gritos e pontapés. 
Alguns cães são muito úteis na luta com o gado bovino. Quando um vaqueiro 'campeia' acompanhado de seu cachorro, o bicho 'trabalha acuado': cerca o gado aos latidos e morde o boi fujão, impedindo que ele ataque o vaqueiro ou que corra ainda mais. Na perseguição a um boi na mata, sendo o cachorro mais veloz que os humanos, há quem diga que ele 'é mais vaqueiro que o vaqueiro'. A comunicação estabelecida entre humanos e cães em tais momentos é essencial: o bicho 'dá a notícia' de que o boi foi encontrado, de forma que 'trabalhar acuado' significa também comunicar aos humanos o que ocorre.

Caçando, ${ }^{5}$ os cachorros encontram uma de suas maiores utilidades, pois para além de agirem como uma extensão sensorial dos caçadores, seu corpo e suas afecções lhes possibilitam fazer o que os humanos não podem. Na caça, um bom cachorro é aquele que conjuga faro apurado, boa comunicação com os humanos por meio dos latidos e da cinesia, grande disposição para o movimento e destreza que lhe permita partir com determinação, com 'opinião', em busca da presa.

Antes de tudo isso, os cães 'pastoram'.

Pastoreio se refere não a uma atividade de trabalho específica - como é o caso com "agricultura" ou "pecuária" -, mas a uma atitude no mundo e em face das coisas e dos viventes diversos que o habitam. Ao pastorarem, os sertanejos e os seus cachorros estão atentos àquilo ou àquele que é objeto de tal ação com o intuito de tomar uma atitude julgada apropriada quando ela se fizer necessária; mas cães e humanos também podem pastorar para 'tomar conhecimento' acerca daquilo que observam, conhecimento este que será oportunamente por eles mobilizado.

Trata-se, portanto, de uma forma de atenção e de observação indissociável de uma ação iminente, isto é, que se efetiva como tal na intervenção imediata ou posterior sobre aquilo que se observa. Essa forma de observação-intervenção é uma atribuição de responsabilidade: aquele que pastora está se afirmando responsável pela vida de outros, humanos ou não, ou pela integridade da cerca, da casa etc. que estão sob a sua atenção. ${ }^{6}$ Ademais, essa atribuição de responsabilidade pode ser considerada inapropriada ou descabida da parte de quem é 'pastorado' - afinal, há quem 'pastore a vida alheia'...

Pastoreio, portanto, dá conta não apenas das técnicas indispensáveis à criação de animais ou mesmo daquelas da prática venatória (pois os caçadores dizem 'pastorar' os veados, os caititus, os jacus etc.), mas também do próprio significado de partilhar a vida com viventes distintos e das reflexões éticas necessárias para tanto. 
Os cães, alguns bem mais que outros, são conhecidos pelos sertanejos como pastoreadores. Quando os humanos não estão suficientemente atentos, são os cães que se afirmam (ou são afirmados) responsáveis pela integridade dos rebanhos, das casas e dos terrenos. Noite adentro, quando dormem os seus donos, ouve-se o latido indicando o trânsito de alguma motocicleta, a aproximação de um desconhecido ou a passagem de guaxinins, gatos do mato etc. nas cercanias. Ao amanhecer, o ocorrido não escapará aos comentários da vizinhança, que buscará compreender aquela mensagem. A partir dessa atentividade e forma de comunicação, pode-se dizer que os cães são também parte de uma sistemática de "vigiar e narrar" (Comerford 2014) e têm papel importante no autoconhecimento de tais vizinhanças rurais e daquilo que nelas ocorre. Embora não possam narrar o ocorrido para seus donos e outros interessados, eles 'alarmam' que algo ocorre e com isso fornecem pistas para que os humanos, imediata ou posteriormente, signifiquem o acontecimento.

Não obstante isso, os cães, assim como os outros animais, são também pastorados. O trânsito dos cachorros é matéria-prima para conversas e um processo de mapeamento (Comerford 2003) e de aparentamento (Teixeira 2014) parecido com aquele que se dirige aos humanos, assim como se dirige, em alguma medida, a eles. Dessa forma, um cachorro não é apenas um cachorro, ele é um cachorro de alguém - um vizinho, um parente, uma pessoa com quem não se tenha relações amistosas etc. - e, portanto, pode ser conectado a uma família, a uma casa, a um sítio. Conhecer tais vínculos é indispensável para (saber como) lidar com eles. Sendo 'de Fulano' ou 'de Sicrano' e concebidos "como extensões não humanas dos seus donos" (Pereira 2015: 82), o que se faz com/contra os cães reverbera na relação estabelecida com o dono deles. Por sua vez, aquilo que os cachorros fazem e o modo de responder a isso também produzem implicações nas relações sociais (Teixeira \& Ayoub 2016).

Partilhando estradas, veredas, cercas e, mais amplamente, uma mesma vizinhança e ambiente rurais, os movimentos animais e humanos são fatos cotidianos, assim como os encontros, as narrativas e os incidentes por eles propiciados. Que um porco entre na roça de um vizinho, que um cachorro avance sobre um transeunte, que uma cabra se misture ao rebanho de outro criador são fatos corriqueiros; mas isso não significa que dilemas éticos não operem em tais acontecimentos ordinários e que não se possa observar o exercício de uma reflexão na execução das próprias ações e/ou na avaliação daquelas de outrem, sejam esses "outros" humanos ou não.

Do ponto de vista dos sertanejos, os animais também possuem o que chamo aqui de "condição ética", pois suas ações (1) suscitam avaliações e julgamentos pelos outros e por si mesmos e são (2) a resultante de um 
processo relacional, dinâmico e permanente de fazimento de si. Contudo, cabe especificar, e esta é uma questão etnográfica, em que consiste a condição ética canina (ou dos animais em geral, se pode dizer), diferenciando-a da humana. Para tanto, é necessário relacionar a já referida questão da responsabilidade a outro tema caro à discussão sobre ética: a liberdade.

\section{Interlúdio: humanos e animais, cristãos e brutos}

Os esforços de definição do humano passam por reflexões sobre o estatuto diferenciado das formas de vida não humana, como observa Ingold (1995). As reflexões euro-americanas - ou, se quisermos, "naturalistas" (Descola 2013) - sobre a humanidade afirmam a "singularidade humana" em face dos outros animais, de modo que "Cada geração reconstrói sua concepção própria de animalidade como uma deficiência de tudo o que apenas nós, os humanos, supostamente temos, inclusive a linguagem, a razão, o intelecto e a consciência moral" (Ingold 1995: 39-40, grifo meu). Keith Thomas (1988) nota que a história dos pensamentos cristãos e filosóficos ocidentais marca uma inegável "falta de concordância" sobre qual aspecto distintivo seria esse que bipartiria humanidade e animalidade, mas as diferentes reflexões em busca desse "esquivo atributo" diferenciador concordam em pelo menos dois pontos: "[1] assumem uma polaridade entre as categorias 'homem' e 'animal"" e "[2] invariavelmente encaram o animal como inferior" (: 37). A radicalidade da distinção entre humanos e animais, à qual outras se associaram (como aquelas entre cultura e natureza, sujeito e objeto etc.), teve papel-chave no projeto "moderno" (Latour 1994). Racionalista, humanista e universalista, esse projeto afirmava o dever humano de conhecer e ampliar o controle do homem (e usar o substantivo masculino não é desproposital) sobre o cosmos e o socius.

Precedido pela síntese escolástica entre, de um lado, as formulações aristotélicas acerca da natureza e da especificidade humanas (Aristóteles 2012) e, de outro, a afirmação da supremacia do Homem sobre o restante da criação divina, o ápice filosófico da superioridade e do predomínio humanos é comumente apontado pela literatura no pensamento de René Descartes ${ }^{7}$ - considerado por Philippe Descola um dos "arquitetos da cosmologia naturalista" (2013: 63). Nesse longo processo histórico de purificação (Latour 1994), fundamentado na (presunção da) superioridade do Homem e no seu dever de conhecer e controlar a natureza, "O humano se distingue do animal a partir de um traço singular que qualifica o primeiro [como sujeito] a partir de uma redução do segundo à condição de objeto" (Süssekind 2018: 163). 
Considerando-se que um dos fundamentos da superioridade humana era sua "consciência moral" - da qual as bestas brutas prescindiriam -, tal projeto, ao afirmar o estatuto de "sujeitos" para os humanos e relegar os animais (como parte da "natureza") à condição de "objetos", tem como alicerce e corolário a afirmação da incapacidade animal de agir eticamente. Entretanto, nas franjas da oposição marcada entre as condições humana e animal, próximo à vida e ao engajamento cotidianos, a questão é mais complexa e nuançada do que fazem crer essas formulações esquemáticas.

Ao se referirem aos animais, sejam eles de criação ou não, os sertanejos costumam dizê-los 'bichos brutos' ou 'brutos'. Qualquer esforço para definir o que são os brutos passa por uma discussão acerca dos humanos e viceversa. Para caracterizar o bruto, os sertanejos fazem referência ao estatuto da pessoa cristã, ao fato de que apenas o ser humano passa pelo rito do batismo, enquanto os animais, não, isto é, se o humano é batizado, o bruto é pagão. A formulação ganha ainda mais sentido na medida em que 'cristão' é comumente usado em sentido mais amplo do que o convencional em língua portuguesa: é um sinônimo de "humano".

Não obstante, a questão do batismo não me parece ser o traço fundamental nas reflexões sertanejas. Tudo se passa como se o batismo fosse uma espécie de determinação em última instância que serve menos para atribuir "humanidade" aos seres humanos e mais para afirmar o estatuto dos brutos como tal - uma espécie de derradeiro fundamento de diferenciação. O entendimento, a ser discutido na próxima seção, que humanos teriam e que os brutos possuiriam em alguma medida parece mais relevante para marcar essa distinção.

Entretanto, por claras e esquemáticas que pareçam, minha impressão ao ouvir tais formulações e ao refletir com eles acerca delas é que, ao passo que cristão e bruto formam uma oposição binária e, idealmente, se referem a viventes que não deveriam ser confundidos, esse modelo, como eles próprios evidenciam, "faz água" frequentemente. As ponderações e as dúvidas acerca do estatuto dos brutos como bichos 'sem entendimento' são comuns porque a vida partilhada com tais bichos e as interações cotidianas e continuadas com eles fazem com que os humanos se defrontem com as peculiaridades morfológicas e etológicas de cada espécime animal, problematizando a comodidade e a rapidez daquele binarismo fácil.

Nesse nível prático e ordinário, as reflexões sertanejas sobre o estatuto dos animais não se fundamentam naquelas referências ao batismo, mas em outro aspecto já mencionado: o entendimento. 


\section{Criação, liberdade e governo do entendimento}

Entendimento não é sinônimo de conhecimento racional e não se refere à capacidade de "bem julgar e de distinguir o verdadeiro do falso" (Descartes 2018: 69-70), mas - a partir da consciência do lugar que se ocupa em um mundo habitado por viventes diversos - descreve o contínuo exercício de reflexão ética indispensável para se viver produtivamente com os outros, com os seus e consigo mesmo. Por essa razão, tampouco se poderia dizer que o entendimento é tão somente um processo e um projeto individuais de "autoformação", pois isso obliteraria as decisivas interações com outros viventes que nele agem. No mais, ao falarem em 'entendimento', os sertanejos não estão fazendo referência a preceitos morais fixos que deveriam ser necessária e indubitavelmente seguidos, mas sim à capacidade de refletir eticamente sobre o próprio lugar no mundo e, por consequência, sobre as próprias ações e as ações dos outros, assim como sobre as implicações delas. ${ }^{8}$

Embora em ocasiões específicas as pessoas possam ser ditas 'sem entendimento' ou mesmo, em uma disputa com vizinhos, possam 'não chegar a um entendimento', há uma fase específica da vida em que os cristãos são ditos com pouco ou mesmo 'sem entendimento': a primeira infância.

Crianças e brutos são ditos sem entendimento e, por isso, 'inocentes': nos termos de Maya Mayblin (2010), não saíram de um estado inicial de 'inocência' para outro de "conhecimento" das coisas do mundo. ${ }^{9}$ A partir de pesquisa realizada em uma comunidade rural no sertão pernambucano, Mayblin nota que se o "conhecimento" implica o pecado, ele possibilita o "discernimento", que permite aos humanos diferenciar e avaliar a correção das próprias ações e condutas ou daquelas de outrem. O paradoxo moral da pessoa cristã percebido pela autora é que ao passo que a inocência é "um estado espiritual elevado" (: 149), ela é problemática no que diz respeito à vida prática, pois o "discernimento" é fundamental para uma vida adulta produtiva e mesmo para evitar alguns perigos. Na vida adulta, é ele, por exemplo, que permite que alguém saiba quando outras pessoas estão tramando algo contra ele ou buscando enganá-lo. No que tange à existência de tais perigos na infância, destaco que um interlocutor decidiu improvisar um quebra-molas próximo à sua casa justamente porque seus filhos pequenos brincavam na estrada, o que poderia ocasionar um acidente grave caso alguma motocicleta ou carro trafegasse ali em alta velocidade. Ele observou, entretanto, que quando os filhos estivessem 'mais entendidozinhos', desfaria a lombada, o que de fato ocorreu.

Ao se referirem à criação dos filhos e ao se engajarem nesse processo de constituição da pessoa e de fazimento de alguém como 'filha(o)' e de si mesmo como 'pai' e 'mãe', os sertanejos frisam o esforço de acompanhar e instruir as 
crianças no desenvolvimento do seu 'entendimento'. Crescer é se tornar cada vez mais entendido, e é nessa chave que devemos compreender a expressão 'se entender por [como] gente', comumente usada no Nordeste brasileiro para se referir ao amadurecimento social e cognitivo. Enquanto parte do processo do parentesco, criar é construir proximidade, afeto e consideração (Marcelin 1999; Marques 2014; Alves 2015); produzir identificações, coimplicações e mutualidade (Sahlins 2013); e, a partir da 'luta' de pais e mães (Comerford 1999; Teixeira 2014), garantir que nada de essencial falte à criança. Ademais, refere-se à produção de alguém como uma pessoa 'com entendimento'. ${ }^{10}$

E quanto aos seres brutos, que também são concebidos como 'inocentes' e 'sem entendimento' e igualmente criados pelos humanos?

Embora 'sem entendimento' - entenda-se: sem a mesma forma e qualidade de entendimento de que os humanos são capazes -, Deus dotou os seres brutos com uma porção específica dele. Se o homem 'É aquilo que ele pensar em fazer', como me disse um trabalhador rural, isto é, se tem um entendimento mais amplo e inúmeras possibilidades de florescimento e de realização pessoais, o bruto tem um entendimento para aquilo que é, para as suas circunstâncias. É a defesa, a 'noção medonha das coisas', dada a todos os seres por Deus: o tatu cava buracos, o cachorro fareja, a onça tem agilidade etc. Essa porção de entendimento comumente surpreende os homens quando se deparam com as ações de animais específicos e é ainda, aliada à inocência, a justificativa para determinadas atitudes brutas. Se um burro dá um coice ou um cão morde quem tentava ajudá-lo, não o faz por mal e nem sabe por qual razão o fez: é da sua 'defesa'. É também por isso que não se deveria torturar ou maltratar os brutos: 'inocentes', eles 'não sabem' o que fazem, não têm necessariamente intenção de fazer o mal.

Um ponto que sempre me chamou a atenção no emprego de 'criação' é que, não obstante a polissemia e a amplidão do seu uso (que pode incluir, por exemplo, a criação divina), o termo não é usado pelos interlocutores para descrever a sua relação com as plantas por eles cultivadas. Até onde pude perceber, e em consonância com a literatura sobre diferentes grupos camponeses brasileiros, 'criação' se refere à relação estabelecida com as crianças e com os bichos, sejam eles mais propriamente 'de casa' ou, como os saguis e os macacos-prego capturados ainda filhotes, 'do mato'. $\mathrm{O}$ que o ato de criar tem em comum nesses dois casos é o fato de serem esses engajamentos cotidianos e duradouros com viventes concebidos como sujeitos, embora com capacidades e estatutos ontológicos diferentes. Trata-se, tanto em um caso como no outro, de uma relação intersubjetiva que, idealmente, exige o cuidado, o afeto e a responsabilidade, mas que necessita, com propósitos e métodos variados, do governo da vontade do Outro de forma a auxiliar o desenvolvimento do seu entendimento. 
O uso do conceito de "governo" remete às formulações de Michel Foucault (e.g., 1982, 2006a, 2006b), mas, embora haja semelhanças com elas, falo em governo porque, como o uso de itálico evidencia, não se trata de uma palavra qualquer ou de uma categoria analítica, mas de uma forma sertaneja de fazer referência à liberdade, ou à ausência dela, do sujeito ético.

Governar-se é se afirmar como sujeito livre, é afirmar a autonomia da própria vontade. Mas, para além do cuidado consigo, o governo é ainda mais imperativo na relação com aqueles que se cria, que precisam ser cuidados. Portanto, o ato de cuidar de outros não é percebido pelos interlocutores como a antítese moral do governo dos seus, mas como parte indispensável dele, não obstante a relação de governo nesse sentido ser assimétrica e entre seres concebidos como diferentes. Quando pais e mães afirmam que seus filhos 'Não têm querer', estão destacando o fato de que a sua vontade e os seus desejos estão sujeitos às vontades e aos desejos daqueles que os criam. Com isso, marcam uma relação de hierarquia que em boa medida é moralmente justificada pelos genitores em razão do pouco entendimento das crianças e dos jovens. Esse 'Não tem querer' por vezes assume, justamente, a forma de 'Você não se governa'.

No que tange à criação e ao pastoreio dos animais, penso que é possível aproximar as formulações sertanejas daquelas de Michel Foucault com a condição de que se faça uma espécie de "engenharia reversa" na sua formulação sobre o "poder pastoral" (Foucault 1982), retornando assim à origem da sua metáfora do poder. O jogo entre cuidado do todo do rebanho e cuidado individualizado, que exige um necessário conhecimento das idiossincrasias de cada bicho, "Implica um saber da consciência [de cada ser] e a capacidade de dirigi-la" (: 783). É necessário, pois, exercitar uma forma de governo (para falar agora como os sertanejos) que exige "Salvar cada um dos indivíduos do rebanho, mas preocupar-se igualmente com a coletividade", como observa Ariane Vasques (2016: 40) ao pensar sobre a criação de caprinos no sertão pernambucano.

Ressalvadas as diferenças mais notáveis, espera-se dos bichos de criação e das crianças que 'saibam viver' com os outros. Assim como o entendimento dos filhos deve ser cultivado pelos pais, também aquele dos bichos de criação - consideradas as suas circunstâncias brutas e as especificidades de cada espécie animal - deve ser cultivado e desenvolvido. Luzimar Pereira, pensando sobre os camponeses mineiros por ele estudados, nota que "Um dos elementos distintivos da pedagogia urucuiana voltada para os animais evoca a noção de peleja: luta, desafio, enfrentamento" (2015: 71), o que está em consonância com as observações de Virgílio (2019) sobre a criação de animais no sertão cearense como uma "peleja", em que é preciso lidar com 
as idiossincrasias de cada bicho. Dito de outro modo, a condição bruta, do ponto de vista dos humanos que lutam com esses bichos, é também uma condição de recalcitrância. É ela que deve ser conduzida a partir daquela forma de observação interventiva, o pastoreio, e desta forma de autoridade e cuidado, o governo. Todavia, mesmo brutos e passíveis de repreensões e correções físicas mais fortes do que aquelas dirigidas às crianças, os bichos são, ao menos em princípio, inocentes e, por isso, não podem apanhar excessivamente ou tão somente porque aquele que os ataca assim quer.

Entendimento, pois, é essa qualidade indispensável para a vida de seres que não podem ser concebidos apenas em si, isto é, desvinculados das suas relações com outros seres, sejam eles considerados semelhantes ou não. É por isso e para isso mesmo - em diálogo com a leitura de James Laidlaw das formulações de Foucault - uma "prática consciente (refletida) da liberdade" (Laidlaw 2002: 324). As concepções sertanejas do pastoreio e do governo evidenciam que, de modo parecido ao que Lambek defende (2015: 7), a liberdade não significa a total independência em relação a regras, obrigações ou convenções, mas sim - informado por critérios, compromissos, pertencimentos e valores diversos e incomensuráveis - a capacidade de compor caminhos entre elas e a partir delas. A necessidade de governar o próprio entendimento e daqueles que estão sob sua responsabilidade, intervindo quando se julgar necessário, evidencia a tensão entre "liberdade" e "obrigação" constitutiva dessa vida ordinária que, de maneira indispensável, se vive com outros.

No que tange aos animais de criação, as idiossincrasias de alguns bichos exemplificam tal tensão e demonstram como as ações animais são eticamente percebidas, como há expectativa de algum entendimento da sua parte: ${ }^{11}$ o cavalo velhaco, o boi ladrão, o cachorro viciado (um vocabulário também usado para descrever e avaliar a conduta humana) etc. Deve-se tomar alguma atitude para com eles, que pode ser coletiva.

Diferentes situações por mim presenciadas e a mim relatadas evidenciam isso. O pequeno proprietário que precisou vender seus porcos, que criava soltos, porque eles 'aprenderam' a, repetidamente, ir comer nas terras de um fazendeiro vizinho; a cerca que foi reformada porque um bode teimava em passar por ela e devastava a roça de um confinante; os muitos episódios de burros e jumentos que tiveram uma pata dianteira e uma traseira amarradas para impedi-los de pular cercas e 'roubar'; e é também o caso desses cachorros que, viciados, 'pegam' criação e problematizam a inocência que caracterizaria os brutos. 


\section{O vício como limite ao entendimento e à inocência}

Do alpendre da casa de um trabalhador rural, onde ele e alguns vizinhos conversavam, vimos quando um pequeno proprietário, vindo de uma localidade a cerca de $8 \mathrm{~km}$ dali, chegou e parou sua motocicleta no terreiro. Contrariado, Miguel da Bia contou que, naquela manhã, um cachorro atacou suas ovelhas. Do seu sítio até onde estávamos, passou nas casas buscando identificar o animal: parava nos alpendres e terreiros, se inteirava das novidades e comunicava suas intenções. Miguel nos descreveu pormenorizadamente o bicho que vira, pois alguém talvez reconhecesse o cachorro 'vermelho com lombo roxo, quase preto'. Como tal animal poderia ser de alguém dali, os presentes trataram logo de dizer que não era esse o caso, apontando as diferenças entre seus próprios animais e aquele descrito.

Miguel da Bia contou que, anos antes, alguns cachorros da sua vizinhança mataram sete ovelhas suas. Ele se dirigiu à casa dos donos, mas um deles, Françuá, se recusou a tomar alguma das providências comumente colocadas: 'Nem matava o cachorro, nem pagava nem um centavo'. Miguel respondeu: 'o senhor pode criar seu cachorro, o senhor tá dizendo que não vai pagar a criação, mas o senhor vai pagar a criação e vai ser bem pago'. Em seguida, ele foi à cidade para denunciar o ocorrido. Como de praxe, a notícia correu rapidamente - 'não sei quem foi que disse a ele que me viu conversando com o delegado' - e Françuá se viu obrigado a matar o cachorro antes da possível visita da força policial.

Por sua vez, Marco, um pequeno proprietário que mora em um sítio vizinho ao de Miguel da Bia, conta uma história que exemplifica o imperativo de matar o animal, mesmo quando ele desempenha bem alguma atividade que lhe cabe. Certa vez, quando seu filho e um vizinho foram caçar, eles ouviram o latido do cachorro que os acompanhava. Seguindo naquela direção, viram uma ovelha morta. O cachorro, que se revelava um bom caçador, estava ao lado dela e manchado de sangue. O filho contou ao pai o que ocorrera e Marco narrou detalhadamente o que se seguiu ao relato:

Rapaz, o bicho adivinha: nem pra casa ele veio, ele ficou ali na calçada. Aí chamei, ele veio animado danado. Peguei a espingarda ali, botei ele lá no quintal grande... Mas o que, meu amigo?! É bicho esperto, menino! Não veio. Eu chamava, ele não vinha nem a pau, ficou lá. Eu atirei só com chumbo [como] daqui na cerca, pegou na cara dele, ele ficou aos alarmes. Aí eu vi que ele não morria: peguei um pau, desci o pau, o pau quebrou. Aí digo: Espera aí, que cê morre! Aí corri ali dentro do quartinho, peguei o machado, meti-lhe o machado: esbagacei a cabeça dele! Aí peguei e rebolei por cima da cerca lá pro outro lado. Digo: Esse daí não vai pegar ovelha mais não. 
Situação parecida também ocorreu com Renato, 'morador' em uma propriedade rural no município de Catarina. Conhecido como bom caçador, sobretudo de porcos caititus, Renato já 'possuiu', como se diz, diferentes cachorros. Certa feita, um deles atacou um 'borrego' (um cordeiro) de Evilásio, um vizinho pecuarista. O fato de ser um filhote de no máximo dez dias de nascido aumentou ainda mais a ira do dono: 'Pegou na cernelha do borreguinho assim e deu uma mordida, aí o borreguinho tava lá caído, pelejando pra se levantar, mas tava sem ânimo. Aí ele [o cão], quando me viu, foi e correu. Aí eu digo, Ah, filho de uma égua! A gente fica logo irado de raiva, né?'. Naquele mesmo dia, havia uma reunião da associação da comunidade rural em que ele e o dono do cordeiro viviam. Ele comunicou o ocorrido a Evilásio, que disse a Renato não ser necessário matar o cão, já que era a primeira vez que fazia isso, mas, lançando mão de uma metáfora para lá de curiosa, o dono dos cachorros observa que o bicho que havia matado poderia ensinar esse tipo de conduta aos demais que possuía: 'O bicho pegando a primeira vez fica viciado. Uma ovelha só bota um rebanho a perder: ele pegou sozinho, outro dia pegava mais o outro, aí desgraçava o outro cachorro também, né?'.

Em outra ocasião, quando foi o cachorro de um vizinho e uma cadela a atacarem o seu próprio rebanho, Renato se dirigiu ao seu dono para comunicar o ocorrido. Ele ficou surpreso com o fato de que o vizinho ainda não havia matado o cão, mas Renato ponderou que era desejável primeiro informar ao dono do bicho. A outra cadela que protagonizou o ataque não tinha dono. Quando Renato se aproximava da cadela para matá-la, a surpresa: tão logo chegou perto, sem dar qualquer demonstração do que faria, ela correu. O fato de a cadela ter fugido com a mera presença de Renato foi por ele percebido como uma evidência da sensibilidade e consciência caninas: 'para você ver como quando o bicho deve [isto é, quando fez algo considerado errado], o bicho é brabo'.

Contudo, nem sempre é a criação dos vizinhos aquela ameaçada pelos cães: há casos em que eles atacam as ovelhas do seu próprio dono. Aliás, a mera disposição de fazê-lo já pode motivar alguém a tomar a atitude apropriada. Depois de mencionar as qualidades de uma cadela que possuía, Hermes conta que o bicho vinha demonstrando em diferentes ocasiões animosidade em relação ao rebanho, o que não cessou mesmo com repreensões físicas mais fortes. Vendo outra vez a cadela perseguir suas ovelhas, e ainda com maior obstinação, ele tomou a atitude radical de matá-la: 'Não, antes de ela pegar, eu vou ajeitar'.

É o mesmo Hermes quem narra uma ocasião em que, trabalhando na roça, presenciou dois cães seus - cães esses que, por serem bons caçadores, 'não dava [vendia] por dinheiro nenhum' - atacando um carneiro 
de Candinho, um vizinho muito seu amigo. Depois de ter matado os companheiros com a foice com a qual trabalhava, ele comunicou o ocorrido ao vizinho, mas não mencionou que os cães já estavam mortos. Ouviu educadamente do criador que, a partir de então, mantivesse os cachorros amarrados. Mais tarde, tendo visto com os próprios olhos que Hermes matara os cães, Candinho disse ao vizinho que não carecia de tê-lo feito, pois 'os bichinhos são brutos'. Depois de dizer que 'corda de amarrar cachorro que pega ovelha é aquela [a morte]', Hermes respondeu à afirmação do vizinho: 'É, mas o bruto também entende quando faz uma coisa errada, seu Candinho'. Como evidência desse entendimento canino, Hermes conta que tão logo o carneiro foi sangrado, chamou os cães para junto de si, mas, vendo que o dono estava com raiva deles - 'os bichos conhecem, sabia?' -, não se aproximaram. Os bichos chegaram perto do dono apenas quando Hermes misturou rapadura e água em uma cabaça e ofereceu a mistura para eles.

Esse conjunto de relatos, e são poucos em relação à quantidade que ouvi e às situações que presenciei, demonstra pelo menos três pontos interessantes para o que discutimos aqui sobre a condição ética dos cães.

(1) Evidenciam-se os sentimentos de frustração, raiva e tristeza que acometem os donos dos cães, que se veem obrigados (ou constrangidos) a matá-los ou a se desfazer deles de alguma forma. A frustração e a raiva são compreensíveis considerando que, de um lado, o embaraço da situação pode comprometer a relação com vizinhos, 'conhecidos' e amigos e, de outro, que em todas as situações acima relatadas os cães que foram mortos cumpriam bem os papéis que seus donos lhes haviam atribuído ou para os quais os próprios bichos haviam demonstrado vocação: eram bons caçadores, bons 'pastoradores' e, de modo geral, bons companheiros. Se a tristeza segue de perto a frustração, é porque os anos de convivência e as sucessivas demonstrações de lealdade e perícia fizeram com que os humanos se apegassem aos seus cães, daí Hermes dizer, ao rememorar a segunda situação acima relatada, que 'Fi[cou] com raiva: você confiar nas coisas e dar o contrário... né?' .

A ação ou a reiterada disposição de atacar os rebanhos ovinos compromete severamente a lealdade e o afeto construídos, justificando moralmente, do ponto de vista humano, o ato extremado de matar o animal. Tal frustração é tanto maior na medida em que, como visto em seção anterior, dos cães se espera justamente o 'pastoreio', isto é, assumir a responsabilidade junto aos seus donos de garantir a integridade da 'criação'. A título de comparação, quando os cães estão velhos, debilitados e/ou doentes (sobretudo quando sua enfermidade é concebida como transmissível para humanos ou outros bichos), os donos podem pedir que amigos ou vizinhos 
os matem, talvez porque a tristeza de ter que fazê-lo seja considerável. Embora eles possam proceder da mesma forma quando os seus cães atacam 'criação', minha impressão é que nesse caso é mais comum que os donos o façam sem tanto remorso.

(2) Nos relatos de Marco, Renato e Hermes, fica clara a percepção humana de que os cães têm consciência de que tomaram uma má decisão, ou seja, que fizeram algo 'errado', daí evitarem se aproximar dos próprios donos depois do ataque. É o próprio Hermes quem me narra a situação em que, pensando morder um tatu que fugia de um buraco, seu cão acabou mordendo e safanando com força a mão do próprio dono. Hermes conta que tão logo o cachorro 'sentiu' o que fazia, 'ele ficou triste' e acabrunhado: 'Parece que veio na mente dele que ele tava mordendo coisa errada, que tava no lugar errado'. Se, inicialmente, teve o impulso de matar o companheiro, perceber que o cachorro havia se entristecido com o que fizera o fez mudar de ideia: se o matasse, ele diz, seria ele a agir como um bruto.

Os bichos 'sentem' que agiram de forma inapropriada, eles 'conhecem' que os donos estão com raiva deles, assim como, em determinadas situações, podem aprender condutas a partir das ações humanas ou de outros cães, daí a expectativa de Hermes de governar o entendimento da cadela ao aplicar-lhe punições físicas ou a atitude de Renato de matar o seu cachorro que atacou as ovelhas de um vizinho para impedir que seus outros cães aprendessem com ele essa conduta. Nesse sentido, a troca de impressões entre Candinho e Hermes me parece exemplar do curto-circuito moral de que falo neste artigo: ao passo que o primeiro fez referência à condição bruta dos cachorros para ressaltar a sua inocência e, no limite, inimputabilidade, Hermes apontou que a dose de entendimento canina permitia que 'entendessem' que haviam feito algo errado, o que a reação dos seus cães (mas também dos outros acima citados) demonstrava.

(3) É em razão do vício que a solução mais apropriada é matar, pois 'Cachorro que pega criação não deixa nunca [de fazê-lo]'. E não adianta amarrá-lo, pois 'no dia que você soltar, ele pega de novo'.

Existe um adágio, um 'dizer', comum no sertão nordestino que versa sobre esses cachorros. Ele é citado aqui nas palavras de Oswaldo Lamartine, mas já ouvi os interlocutores dizerem que "Homem que bebe e joga/ Mulher que errou uma vez/ Cachorro que pega bode/ Coitadinho desses três" (1980: 218). O "coitadinho" do ditado passa a ideia de um fim amargo reservado aos três, mas, ao citá-los em conjunto, destaca algo mais: eles se igualam por terem uma mesma falha moral que dificulta a sua capacidade de bem agir e os impede de entender plenamente as implicações das suas ações, embora possam sentir remorso depois de fazê-las. O vício, portanto, é concebido como 
uma disposição continuada, contraproducente e moralmente condenável que dificilmente pode ser reformada.

Porque o prazer proporcionado pela atividade leva o viciado a repeti-la, quando os sertanejos caracterizam um humano ou um bruto como 'viciado', eles tanto estão julgando negativamente a sua conduta como destacando a sua previsibilidade mesmo em circunstâncias desfavoráveis e/ou quando é perigoso e danoso para si e/ou para outrem fazê-lo. No caso dos brutos, tal previsibilidade é uma espécie de desdobramento da recalcitrância de que falei anteriormente.

Se alguns dos meus interlocutores eram 'viciados' no consumo de bebidas alcoólicas e largaram o vício de uma vez por todas, embora a duras penas, não parece, nos relatos, que essa possibilidade exista para os cães. ${ }^{12}$ Não adiantaria amarrá-los ou, como fez Hermes, bater neles, ou, como fez outro interlocutor, dá-los para outra pessoa, pois uma vez pegador de criação, sempre assim: 'parece, rapaz, que tem um chama [atração], o sangue da criação tem um chama, vicia'. É uma 'inclinação', me diria outro sertanejo, que alguns cachorros têm, enquanto outros, não; mas que, no segundo caso, pode ser corrigida, diz ele, caso o dono, ao presenciar o cachorro ainda pequeno começando a 'estranhar' e correr atrás dos rebanhos, o repreenda de pronto. ${ }^{13}$ Não fazendo isso, ele 'já se vicia'. Mesmo sem 'inclinação', também parece claro que os cães podem aprender tal conduta inapropriada com aqueles que a tenham ou que possam, sem demonstração prévia ou explicação mais evidente, passar a atacar rebanhos. A atribuição a priori de inocência aos brutos tem, portanto, sua limitação prática na vida ordinária: a regularidade da conduta (mesmo com todas as repreensões que visam freá-la) e as demonstrações dos cães de que 'entendem' ter feito algo errado evidenciam isso.

Sendo o cachorro um bruto, não possuindo pleno entendimento, o dono não tem, a priori, culpa do mal feito pelo bicho; entretanto, se o dono não se desfaz do cão ao descobrir o vício, ele estará assumindo a responsabilidade pelos atos do animal. Nesse caso, se o prejuízo não se paga com o sangue do cachorro, os sertanejos dizem que ele se paga com dinheiro, e assim se pagará nas outras ocasiões em que a criação for atacada. ${ }^{14} \mathrm{Na}$ ética ordinária do pastoreio sertanejo, a contraparte da falta de entendimento dos animais deve(ria) ser o necessário entendimento do seu dono, uma demonstração da sua consideração pelos vizinhos.

Manter vivo um cachorro que todos sabem pegar criação pode trazer outro problema para seu dono: se alguma ovelha for atacada nas redondezas, a suspeita (ou a certeza) dirigir-se-á àquele que é já reconhecido como capaz de fazê-lo. Assim como circulam os humanos e os bichos, circulam as 
narrativas e, com elas, a fama ou a reputação dos seus personagens: 'Às vezes, vem um cachorro do [sítio] Alto Belo, do [sítio] Angico, mas só paga o meu, porque o meu tem a fama'. Ao observar isso, Hermes critica vizinhos que, enfurecidos com os ataques aos seus animais, mataram subterraneamente cachorros que ele acreditava nada terem a ver com o ocorrido. ${ }^{15}$

Quando um cachorro é reputado como 'pegador de criação' e o seu dono como 'mal vizinho' ou 'sem consideração pelos vizinhos', atos contingentes se expandem espaço-temporalmente e permanecem presentes nas narrativas (Munn 1992: 117), orientando ações e expectativas subsequentes em relação a ambos. Na medida em que o vício se constitui como tal a partir de uma conduta regular, há expectativas de que os viciados tornem a agir da forma que agem, o que explica a culpabilização de cães que já tenham atacado rebanhos. Sendo a fama um "diálogo social" (Marques 2002: 104), sendo as performances de membros de coletividades familiares capazes de reforçar ou atualizar a reputação de tais coletividades, nelas podendo produzir segmentações (Marques 2005), cães e outros animais de criação são interlocutores com papel decisivo em tal "diálogo", deixando ver que suas ações e as ações dos seus donos estão eticamente englobadas e se co-constituem.

\section{Considerações finais}

Se o Ser bruto guarda grande distância em relação ao Ser humano, as falas mais prosaicas, os relatos mais bem elaborados e as situações ordinárias presenciadas em campo evidenciam que humanos e animais, consideradas as especificidades e as possibilidades do seu entendimento, são concebidos como sujeitos éticos. Ao passo que há modos apropriados de ser e de agir enquanto humano - e eles, por certo, variam conforme as circunstâncias de cada um -, o que a discussão precedente evidencia é que também há expectativas e modos apropriados de ser animal.

Ao esperar que os donos se responsabilizem pelos atos dos seus animais de criação, afirma-se, para além dos limites do entendimento dos segundos e do necessário cuidado no trato cotidiano com os vizinhos, a complexa ambiguidade que constitui esses animais como 'de criação' ou domésticos. Se, de um lado, são propriedade e podem ser mortos, vendidos, dados, emprestados etc., de outro, não são matéria inerte. Como observa Cimea Bevilaqua - ao descrever o curto-circuito jurídico produzido pelos ataques de cães "perigosos" a seres humanos -, malgrado os cachorros sejam res (coisas) incorporados ao patrimônio das personae (pessoas), os cães têm direitos, 
estatuto de pessoa, intencionalidade, "autonomia da vontade" (2011: 217) e "se d[ão] a conhecer pelos efeitos de suas ações sobre outros - animais, seres humanos e objetos inanimados, mas também normas, procedimentos e decisões judiciais [...]" (2016: 379).

Andriolli e Pereira (2016: 94) também destacam tal ambiguidade ao notar que nos sítios de Urucuia e Chapada Gaúcha (MG) o fato de os animais de criação serem concebidos como "objetos de posse de alguém ou de uma família" não significa que não possam estabelecer relações intersubjetivas com os humanos e que não tenham "intenções e agências". Para além desse eixo de relações (em que os animais podem ocupar o polo de sujeitos ou de objetos), os autores observam que as relações que os humanos estabelecem com eles podem também ser de confiança ou de desconfiança, o que a discussão precedente evidencia.

Ora, se tais relações podem ser concebidas a partir das chaves da confiança e da desconfiança é, em larga medida, em razão das ações dos próprios bichos e, diriam os sertanejos, das demonstrações do seu entendimento. Cotidianamente, animais e humanos (re)produzem as próprias reputações e, ao fazê-lo, também (re)produzem as reputações uns dos outros em um englobamento que se até pode ser informado pela relação de propriedade - isto é, pelo fato de os primeiros serem 'possuídos' pelos segundos -, vai além dela.

Ao chamar a atenção para esses aspectos, os dados aqui apresentados permitem complexificar o tratamento dado pelos autores citados na introdução deste artigo ao tema da ética. Como observamos, as relações entre humanos e animais não são um foco de atenção etnográfica dessa literatura ${ }^{16}$ e o tratamento teórico dado ao tema é ou insuficiente, ou problemático.

Objetivando não reforçar um "grande divisor" e fazendo referência ao "pós-humanismo", Michael Lambek (2015: 15), por exemplo, declara-se "neutro" sobre as capacidades de julgamento e de reflexão éticas de outras espécies animais. Por sua vez, James Laidlaw (2014: 105), embora reconheça que " [...] o sujeito ético pode não corresponder exatamente ao que podemos pensar como um animal humano individual", demonstra algum ceticismo quanto à questão e aponta a diferença que há/haveria entre os animais (ou as máquinas) terem "significado ético para nós" e serem, em si, "sujeitos éticos". Considerando pesquisas etnográficas que trataram sobre as relações entre humanos e animais em sociedades de pastores e de caçadores e coletores, o autor defende, por exemplo, que o trabalho ético em jogo em tais relações seria desempenhado exclusivamente pelos humanos, não pelos animais (: 107). Assim, no que diz respeito às discussões sobre ética e moralidade, parece-me que ao estabelecer uma distinção entre, de um 
lado, "sujeitos éticos" e, de outro, seres ou coisas com "significado ético para nós", Laidlaw acaba, na prática, vinculando termo a termo tal oposição àquela entre humano e não humano, mas também àquelas entre cultura e natureza, sujeito e objeto.

Em suma, as formulações sertanejas evidenciam que a separação entre "humanos" e "animais" não coincide termo a termo com aquela entre o "ético" e o "não ético". Para os sertanejos, os animais são simultaneamente percebidos como "sujeitos" e "objetos", o que se deixa ver na necessidade de serem criados, pastorados e de se exercer um governo sobre eles de modo a acompanhar o desenvolvimento do seu entendimento.

Afirmar o que chamo aqui de condição ética dos cães, ou seja, afirmar que são concebidos como sujeitos éticos, não é o mesmo que igualar tal condição àquela dos humanos, como os apontamentos sobre o vício e a (im)possibilidade de correção da conduta viciada mostraram. Conceber seres diferentes como "sujeitos" não implica afirmar que seu estatuto e sua capacidade de ação sejam os mesmos. Fundamentalmente, conceber ou não os animais como "sujeitos éticos", apontando as suas possibilidades de ação e de reflexão, é uma questão etnográfica; mas, para tanto, é necessário romper uma amarra teórica.

O impasse que leva a optar pela consideração dos animais ou como agentes "copartícipes da vida social" ou como "símbolos" e objetos é estéril, na medida em que as ações dos animais podem contribuir decisivamente para a "rica simbolização" que a eles se dirige (Vander Velden 2015: 9). Assim, os sertanejos apontam que o "significado ético" que os cães ou um cão específico têm para eles não pode ser separado da sua condição de "sujeitos éticos", pois, em boa medida, dela deriva.

Investimentos etnográficos sobre a ética ordinária da criação de animais nos farão refletir sobre como as chamadas sociedades camponesas e/ou pastoris pensam e vivem com os animais, mas também nos permitirão ver quanto a intencionalidade e a condição ética desses bichos revelam aspectos insuspeitos sobre aquilo que nos perguntamos acerca da socialidade rural e do estatuto ontológico de humanos e animais. 
Recebido em 17 de agosto de 2020

Aprovado em 22 de setembro de 2020

Jorge Luan Teixeira

Professor do curso de Ciências Sociais da Universidade Estadual Vale do Acaraú (UVA). Mestre e Doutor em Antropologia Social pelo Museu Nacional/UFRJ. É pesquisador do Núcleo de Estudos, Pesquisa e Extensão em Desenvolvimento e Território (NEDET) da UVA e do Núcleo de Antropologia da Política (NuAP), vinculado ao PPGAS/MN/UFRJ. Desenvolve investigações na área de Antropologia Rural com foco nos seguintes temas: mobilidade, família e parentesco; ética, técnica e ambiente; relações entre humanos e animais.

https://orcid.org/0000-0001-7729-3823

E-mail: jorge.luant@gmail.com 


\section{Notas}

1 Este artigo tem por base pesquisa etnográfica nos municípios de Catarina e Saboeiro, no Sertão dos Inhamuns (CE). O trabalho de campo foi realizado de maneira intermitente entre 2013 e 2019, totalizando, aproximadamente, 12 meses. A pesquisa que desenvolvo desde 2015 nessa região, e que resultou na minha tese de doutorado (Teixeira 2019), tem como foco as atividades de caça realizadas por populações rurais. Ressalto que, em razão da controvérsia moral e da ilegalidade das práticas aqui descritas, os nomes das pessoas foram alterados para impossibilitar que os leitores as identifiquem.

2 Quase todos os interlocutores são ou pequenos proprietários rurais, ou 'moradores' (trabalhadores rurais que residem e trabalham em propriedades alheias). Alguns 'moradores' são também vaqueiros dos rebanhos ovinos, caprinos e/ou bovinos, rebanhos estes criados em um trânsito regular entre os currais, os açudes, as matas e os pastos. Muitos pequenos proprietários e 'moradores' são aparentados e costumam trocar 'dias de serviço' entre si, não havendo diferenças econômicas, sociais, culturais ou étnicas significativas entre eles. Os grandes proprietários - absenteístas, em sua maioria - contam, sobretudo, com a renda provinda dos rebanhos animais e das plantações de milho. Para mais informações, remeto o leitor para outros trabalhos (Teixeira 2014, 2019).

3 Todas as citações de textos em outras línguas foram por mim traduzidas. Falas dos interlocutores são destacadas com aspas simples e as menções a conceitos ou formulações suas ou estão entre aspas simples, ou em itálico. Palavras em língua estrangeira também estão destacadas em itálico.

4 Com exceção de uma única cadela, todos os cães que conheci em campo não tinham raça definida. $\mathrm{O}$ alto valor atribuído a um cão provém das habilidades que de fato demonstra e/ou, em menor medida, por ser ele descendente de cães que desempenhavam bem alguma atividade. O preço elevado, portanto, não tem ligação com a "pureza" de uma raça específica ou com a conformidade do cão aos padrões estabelecidos ao longo de gerações por criadores e cinófilos.

5 A caça na região estudada é realizada por homens casados e por jovens solteiros do sexo masculino. Embora esta separação seja mais esquemática do que ocorre na prática, pode-se dizer que os interlocutores (1) caçam com o auxílio de cães; (2) com espingardas, montando esperas para pastorar bichos como veados e caititus, ou de maneira mais ativa, caminhando pelas matas à procura de aves e de pássaros; e (3) fazendo uso de armadilhas, como as arapucas, os laços e as tatuzeiras. A escolha de uma estratégia e de técnicas específicas de caça depende das características do terreno, da estação do ano, das preferências e da idade do caçador, assim como das peculiaridades da espécie ou de um animal singular (Teixeira 2019).

6 Embora, por limitações de espaço e em razão do escopo deste artigo, não seja possível me aprofundar neste ponto, ressalto que os seres encantados que são donos da caça também são concebidos pelos interlocutores como 'pastoradores' e responsáveis 
pela integridade desses bichos. São esses seres encantados que governam os bichos do mato e deles cuidam, no que há paralelos evidentes com a literatura da Etnologia Indígena das Terras Baixas Sul-Americanas que tratou direta (e.g. Fausto 2008) ou indiretamente (e.g.Vander Velden 2012) do tema das relações de maestria. Ressalte-se, contudo, que as relações entre humanos, animais caçados e donos da caça também foram tema de trabalhos realizados com populações camponeses, como os seringueiros do Acre (e.g. Dias 2004; Almeida 2013).

7 Para Descartes (2018), a "alma" animal é radicalmente diferente da "alma racional" humana, que é independente do corpo e imortal. Em seu pensamento, se humanos e animais possuem "fisicalidades semelhantes" (Descola 2013) - o que se deixa ver na descrição da circulação do sangue (Descartes 2018: 101-108) -, os segundos, embora alguns tenham os órgãos para tanto, prescindem da linguagem e agem não em função da razão, mas como resultado da disposição dos seus órgãos, de modo que "é a natureza que neles age" (: 110).

8 Tratando-se de bibliografia diversa e com grandes diferenças entre si, essa capacidade de ação e de reflexão éticas foi diversamente concebida e conceituada pela(o)s autora(e)s. Para além do "julgamento prático" (Lambek 2010, 2015) influência confessa do conceito aristotélico de "Phronesis" (Lambek 2000) - e da "prática refletida da liberdade" (Laidlaw 2002, 2014) - em diálogo com a obra de Michel Foucault -, cabe destacar, por exemplo, os conceitos de "moral reasoning" (Howell 1997; Sykes 2009) e "momento ético" (Zigon 2009).

9 Tanto entre os camponeses pernambucanos, estudados por Mayblin, como entre os Xukuru, estudados por Clarissa Lima (2013), as aproximações entre o estatuto das crianças e dos brutos são comuns. O batismo, o "sinal da cruz", é percebido como um rito de passagem fundamental para que as crianças se tornem "seres humanos" (Lima 2013: 172) ou "seres humanos morais" (Mayblin 2010: 155). No que tange à inocência, cabe destacar que os Tremembé de Almofala (CE) pensam as crianças que morrem sem passar pelo rito de batismo como "anjinhos" (Gondim 2016), designação também comum na região por mim estudada. Em uma situação etnográfica bastante diversa, as protetoras de gatos de rua estudadas por Andréa Osório (2016: 72) também aproximam os animais abandonados das crianças, pois, assim como elas, são "inocentes, ingênuos, sem responsabilidades e inimputáveis". Tal percepção é visível tanto na infantilização desses bichos quanto na sua designação como "anjinhos", seres incapazes do mal ou de suscitar sentimentos negativos. Por isso mesmo, sua "essência é de uma pureza que a humanidade desconhece, a não ser em tenra infância" (: 73). Como veremos, o vício dos cães problematiza frontalmente esta última concepção.

10 Estudando as andanças dos moradores de Pinheiro (MG) no "mundo", Yara Alves (2015) observa algo parecido: a "sabedoria" indispensável para viver tais deslocamentos vem da "casa raiz" e da mãe, aquela que "cria" e "ensina a ser gente". É a criação que permite alcançar o "equilíbrio", isto é, o "estado mental e corporal necessário para saber viver e conviver, capacidade almejada para um adulto, que já está criado" (2015: 69). 
11 Entre os Karitiana, Vander Velden observa que o "bom comportamento" dos cachorros, seres moralmente ambíguos, é uma das qualidades que fazem deles "sabidos" e prezados pelos seus donos. Deles, talvez pelo fato de serem "criados como gente", se espera maturidade e um conjunto de qualidades que são também esperadas nos Karitiana. Cabe-lhes o que cabe aos humanos: um "saber caçar", mas, fundamentalmente, um "saber viver" (2012: 192), malgrado a ambivalência moral desses companheiros para os Karitiana, que em larga medida provém da sua "potência predatória" e de um "conjunto de hábitos antissociais" (Vander Velden 2016: 27). Descrever uma espécie de "ética do trabalho canino" (: 33) apenas é possível, eu destaco, na medida em que esses bichos (ou alguns deles, pelo menos) têm a capacidade de assim se portar e agir, isto é, são concebidos como sujeitos éticos.

12 Ressalvadas as inegáveis diferenças etnográficas, essas observações lembram aquelas de Anand Pandian (2009) para o caso da comunidade Piramalai Kallar, para quem, no que diz respeito às "criaturas domesticadas", a afeição humana é a contraparte da sua obediência. Para o povo estudado pelo antropólogo indiano, a especificidade da condição humana está ligada justamente ao autocontrole sobre os próprios desejos.

13 Também é desejável que os vizinhos, ao presenciarem esse tipo de atitude, a repreendam e comuniquem o episódio ao dono do cão.

14 Ressalto, contudo, que essa possibilidade de compensação financeira me parece mais uma virtualidade e uma ameaça do que uma solução de fato, pois nunca presenciei tal desenlace.

15 Nesses casos, os criadores podem envenenar os cachorros suspeitos jogando 'bolas' para eles: carne misturada com veneno de rato e, às vezes, pedaços de vidro. Se não podem provar que foram os bichos dos vizinhos os responsáveis pelo ataque, tampouco poderão os vizinhos provar quem jogou as 'bolas'. Trata-se de um procedimento para lá de controverso e perigoso, pois exige o deslocamento daquele que 'joga as bolas' até a casa do dono dos cachorros durante a madrugada. Ayoub (2016) observou que uma estratégia similar é empregada nos faxinais de Pinhão (PR), chegando os cachorros a serem enterrados para que seus donos não os saibam mortos.

16 Chama a atenção que alguns desses trabalhos que versaram sobre as relações entre humanos e animais tenham tomado como provocação, justamente, a morte e a violência para com os segundos (Das 2013; Singh \& Dave 2015; Keane 2018), o que abre margem para considerações morais variadas da parte dos seres humanos acerca da sua própria conduta. Entretanto, levando em conta o sentido que esses autores dão à "ética", não está em questão a capacidade dos animais de refletirem e agirem eticamente. A exceção que conheço quanto a isso é a etnografia de Anand Pandian (2009). 


\section{Referências bibliográficas}

ALMEIDA, Mauro W. Barbosa de. 2013. "Caipora e Outros Conflitos Ontológicos". R@U: Revista de Antropologia da UFSCar, 5 (1): 7-28.

ALVES, Yara. 2015. A Casa Raiz e o Voo de suas Folhas: Família, Movimento e Casa entre os Moradores de Pinheiro - MG. Dissertação de Mestrado, Universidade de São Paulo.

ANDRIOLLI, Carmen. 2011. Sob as Vestes de Sertão Veredas, o Gerais: "Mexer com Criação" no Sertão do IBAMA. Tese de Doutorado, Universidade Estadual de Campinas.

ANDRIOLLI, Carmen \& PEREIRA, Luzimar. 2016. "Os Dilemas da Criação: as Ambiguidades dos Relacionamentos entre Humanos e Não Humanos em dois Municípios Mineiros". Teoria e Cultura, 11 (2): 93-106.

ARISTÓTELES. 2012. De Anima. 2. ed. São Paulo: Ed. 34.

AYOUB, Dibe. 2016. Entre Jagunços e Valentes: Família, Terra e Violência no Interior do Paraná. Tese de Doutorado, Universidade Federal do Rio de Janeiro.

BEVILAQUA, Ciméa. 2011. “Normas Jurídicas e Agências Não humanas: o Caso dos Cães 'Perigosos'". Avá, 19: 199-225.

. 2016. "Direito(s) e Agências Não humanas: como Julgar os Atos de um Animal?". In: C. Bevilaqua \& F. Vander Velden (orgs.), Parentes, Vítimas, Sujeitos: Perspectivas Antropológicas sobre Relações entre Humanos e Animais. Curitiba: EdUFPR; São Carlos: EdUFSCa. pp. 375-405.

COMERFORD, John. 1999. Fazendo a Luta: Sociabilidade, Falas e Rituais na Construção de Organizações
Camponesas. Rio de Janeiro: Relume Dumará.

2003. Como uma Família: Sociabilidade, Territórios de Parentesco e Sindicalismo Rural. Rio de Janeiro: Relume Dumará.

. 2014. "Vigiar e Narrar: sobre Formas de Observação, Narração e Julgamento de Movimentações". Revista de Antropologia, São Paulo, 57 (2): 107-141.

DAS, Veena. 2007. Life and Words: Violence and Descent into the Ordinary. Berkeley: University of California Press.

. 2013. "Being Together with Animals: Death, Violence and Non-cruelty in Hindu Imagination". In: P. Dransart (ed.), Living Beings: Perspectives on Interspecies Engagements. London: Bloomsbury Publising. pp. 17-31. . 2015. "What Does Ordinary Ethics Look Like?" In: M. Lambek; V. Das; D. Fassin \& W. Keane. Four Lectures on Ethics: Anthropological Perspectives. Chicago: HAU Books. pp. 53-125.

DESCARTES, René. 2018. Discurso do Método \& Ensaios. São Paulo: Editora Unesp.

DESCOLA, Philippe. 2013. Beyond Nature and Culture. Chicago: The University of Chicago Press.

DIAS, Carla de Jesus. 2004. Na Floresta onde Vivem Mansos e Brabos: Economia Simbólica de Acesso à Natureza Praticada na Reserva Extrativista do Alto Juruá - Acre. Dissertação de Mestrado, Universidade de Campinas.

FAUSTO, Carlos. 2008. “Donos Demais: Maestria e Domínio na Amazônia". Mana, 14 (2): 329-366.

FOUCAULT, Michel. 1982. "The Subject 
and Power". Critical inquiry, 8 (4): 777-795.

. 2006a. "A Ética do Cuidado de Si como Prática da Liberdade". In:

Ditos e Escritos: Ética, Sexualidade e Política. Vol. 5. 2.ed. Rio de Janeiro: Forense Universitária. pp. 264-287.

2006b. "Uma Estética da Existência". In: _. Ditos e Escritos: Ética, Sexualidade e Política. Vol. 5. 2.ed. Rio de Janeiro: Forense Universitária. pp. 288-293.

GONDIM, Juliana. 2016. Seguindo Trilhas Encantadas: Humanos, Encantados e as Formas de Habitar a Almofala dos Tremembé. Tese de Doutorado, Universidade de São Paulo.

HOWELL, Signe. 1997. "Introduction". In: _ (ed), The Ethnography of Moralities. London and New York: Routledge. pp. 1-20.

INGOLD, Tim. 1995. "Humanidade e Animalidade". Rev. Bras. Ci. Soc., 10 (28): 39-53.

KEANE, Webb. 2018. "Killing Animals: on the Violence of Sacrifice, the Hunt and the Butcher". Anthropology of this century, 22. Disponível em: http://aotcpress.com/articles/killinganimals-violence-sacrifice-huntbutcher/ . Acesso em 24/04/2020.

LAIDLAW, James. 2002. "For an Anthropology of Ethics and Freedom". Journal of the Royal Anthropological Institute, 8 (2): 311-332.

. 2014. The Subject of Virtue: an Anthropology of Ethics and Freedom. Cambridge: Cambridge University Press.

LAMARTINE, Oswaldo. 1980. Sertões do Seridó. Brasília: Senado Federal.

LAMBEK, Michael. 2000. "The Anthropology of Religion and the Quarrel Between Poetry and Philosophy". Current Anthropology, 41 (3) : 309-320.
2010. "Introduction". In: _ (ed.), Ordinary Ethics: Anthropology, Language and Action. New York: Fordham University Press. pp. 1-36. . 2015. The Ethical Condition: Essays on Action, Person and Value. Chicago: The University of Chicago Press.

LATOUR, Bruno. 1994 [1991]. Jamais Fomos Modernos: Ensaio de Antropologia Simétrica. Rio de Janeiro: Ed. 34.

LIMA, Clarissa. 2013. Corpos Abertos: sobre Enfeites e Objetos na Vila de Cimbres (T.I. Xukuru do Ororubá). Dissertação de Mestrado, Universidade Federal de São Carlos.

MARCELIN, Louis. 1999. "A linguagem da casa entre os negros no Recôncavo baiano". Mana, 5 (2): 31-60.

MARQUES, Ana Claudia. 2002. Intrigas e Questões: Vingança de Família e Tramas Sociais no Sertão de Pernambuco. Rio de Janeiro: Relume Dumará.

. 2005. "Notas sobre Valor e Performance nas Relações de Parentesco no Sertão de Pernambuco". Revista USP, 65: 177-184.

. 2014. "Considerações Familiares ou sobre os Frutos do Pomar e da Caatinga".R@U: Revista de Antropologia da UFSCar, 6: 119-129.

MAYBLIN, Maya. 2010. Gender, Catholicism and Morality in Brazil: Virtuous Husbands, Powerful Wives. New York: Palgrave Macmillan.

MUNN, Nancy. 1992. The Fame of Gawa: a Symbolic Study of Value Transformation in a Massim (Papua New Guinea) Society. Durham, London: Duke University Press.

OSÓRIO, Andréa. 2016. "Compaixão, moral e sofrimento animal entre protetores de gatos de rua". Iluminuras, 17 (42): 51-82.

PANDIAN, Anand. 2009. Crooked Stalks: Cultivating Virtue in South India. 
Durham: Duke University Press.

PEREIRA, Luzimar. 2015. "O Movimento dos Bichos: Notas Etnográficas sobre Animais, Seres Humanos e Espaços em Urucuia, MG". Ruris, 9 (1): 63-84.

SAHLINS, Marshall. 2013. What Kinship is - And is Not. Chicago: Chicago University Press.

SINGH, Bhrigupati \& DAVE, Naisargi. 2015. "On the Killing and Killability of Animals: Nonmoral Thoughts for the Antropology of Ethics". Comparative Studies of South Asia, Africa, and the Middle East, 35 (2): 232-245.

SÜSSEKIND, Felipe. 2018. "Sobre a Vida Multiespécie". Revista do Instituto de Estudos Brasileiros, 69: 159-178.

SYKES, Karen. 2009. "Residence: Moral Reasoning in a Common place - Paradoxes of a Global Age. In: (ed.), Ethnographies of Moral Reasoning: Living Paradoxes of a Global Age. New York: Palgrave MacMillan. pp. 3-40.

TEIXEIRA, Jorge Luan. 2014. Na Terra dos Outros: Mobilidade, Trabalho e Parentesco entre os Moradores do Sertão dos Inhamuns (CE). Dissertação de Mestrado, Universidade Federal do Rio de Janeiro.

. 2019. Caçando na Mata Branca: Conhecimento, Movimento e Ética no Sertão Cearense. Tese de Doutorado, Universidade Federal do Rio de Janeiro.

TEIXEIRA, Jorge Luan \& AYOUB,
Dibe. 2016. "Cachorros que Atacam Criação: Reflexões Éticas sobre a Mobilidade e a Vida Social dos Animais em Ambientes Rurais". Iluminuras, 17 (42): 136-165.

THOMAS, Keith. 1988. O Homem e o Mundo Natural: Mudanças de Atitude em Relação às Plantas e aos Animais (1500-1800). São Paulo: Companhia das Letras.

VANDER VELDEN, Felipe. 2012. Inquietas Companhias: sobre os Animais de Criação entre os Karitiana. São Paulo: Alameda. . 2015. "Apresentação ao Dossiê". $R @ U:$ Revista de Antropologia da UFSCAR, 7 (1): 7-16.

. 2016. "Como se Faz um Cachorro Caçador entre os Karitiana (Rondônia)". Teoria e Cultura, 11 (2): 25-35.

VASQUES, Ariane. 2016. As Veredas do Bode: Criação na Solta e Laboro no Sertão de Pernambuco. Dissertação de Mestrado, Universidade Federal de São Carlos.

VIRGÍLIO, Nathan. 2019. "Peleja, Ajuda e Sacrifício na Criação de Animais do 'Povo' do Góis - CE". Mediações: Revista de Ciências Sociais, 24 (3): 42-56.

WILLIAMS, Bernard. 2005. Moral: uma Introdução à Ética. São Paulo: Martins Fontes.

ZIGON, Jarret. 2007. "Moral Breakdown and the Ethical Demand: a Theoretical Framework for an Anthropology of Moralities". Anthropological Theory, 7 (2): 131-150. 
PASTOREIO, GOVERNO E OS

LIMITES DO ENTENDIMENTO: SOBRE A CONDIÇÃO ÉTICA DOS CÃES NO SERTÃO CEARENSE

\section{Resumo}

O artigo discute a condição ética dos cães nos sertões cearenses tomando como foco de atenção os ataques de alguns deles aos rebanhos ovinos. Geralmente levando à morte dos cães, tais episódios produzem uma espécie de curto-circuito moral nas concepções sertanejas sobre os cristãos (humanos) e os brutos (animais) e problematizam a inocência conferida a priori aos segundos. Se os conceitos de pastoreio e governo chamam a atenção para o dever humano de cuidar dos animais de criação e de se responsabilizar pelas suas ações, eles também evidenciam que, para os sertanejos, animais como os cães são capazes de agir e de pensar eticamente. Longe de serem concebidos apenas como seres com "significado ético" para os humanos, os cães são percebidos na vida ordinária como "sujeitos éticos". Este trabalho, portanto, precisa a especificidade dessa condição ética em face daquela dos humanos e argumenta que ambas estão entrelaçadas.

Palavras-chave: Relações humanoanimal, Cães, Ética, Pastoreio, Antropologia rural.
HERDING, GOVERNMENT AND THE

LIMITS OF UNDERSTANDING:

ON THE ETHICAL CONDITION OF

DOGS IN CEARÁ'S HINTERLAND

\section{Abstract}

The article discusses the ethical condition of dogs in the sertão (hinterlands) of Ceará by taking as its subject matter their attacks on flocks of sheep. As a consequence of these events dogs are generally put to death. The events thus put in doubt the innocence previously assigned to these animals and, in so doing, they produce a kind of moral short-circuit on sertanejo conceptions of christians (humans) and brutes (beasts). Not only does herding (pastoreio) and government (governo) shine a light on human obligations to take care of the animals they breed and assume responsibility for their actions, they also stress that, from the sertanejos's perspective, animals like dogs are capable of ethical reasoning and acting. Far from being conceived as beings with mere ethical significance to humans, dogs are ordinarily perceived as ethical subjects themselves. This paper therefore reflects upon the specificity of that ethical condition in dialogue with the human one and argues that they are interwoven. Key words: Human-Animal Relations; Dogs; Ethics; Herding; Rural Anthropology. 
PASTOREO, GOBIERNO Y LOS

LÍM ITES DEL ENTENDIMIENTO:

SOBRE LA CONDICIÓN ÉTICA DE

LOS PERROS EN EL

SERTÃO CEARENSE

\section{Resumen}

Este artículo discute la condición ética de los perros en el Sertão Cearense, tomando como foco de análisis los ataques que algunos de ellos realizan sobre los rebaños ovinos. Esos episodios, que generalmente llevan a la muerte de los perros, producen una especie de cortocircuito moral en las concepciones locales sobre los cristianos (humanos) y los brutos (animales), y problematizan la inocencia que se les confiere a priori a los segundos. Si los conceptos de pastoreo y gobierno llaman la atención sobre el deber humano de cuidar y responsabilizarse por las acciones de los animales de cría, también evidencian que, para los habitantes de la región, los perros son animales capaces de actuar y pensar éticamente. Lejos de ser concebidos solamente como seres con "significado ético" para los humanos, los perros son percibidos en la vida cotidiana como "sujetos éticos". Este trabajo, por lo tanto, establece la especificidad de esa condición ética frente a aquella propia de los humanos, y argumenta que ambas se encuentran entrelazadas.

Palabras clave: relaciones humanoanimal; perros; ética; pastoreo; Antropología Rural. 